\title{
FEIRANTES DO EXTREMO SUL PIAUIENSE: PERCEPÇÃO AMBIENTAL E PRODUÇÃO DE REŞÍDUOS SÓLIDOS
}

\author{
Joselma Bezerra Souza ${ }^{1}$ \\ Karen Veloso Ribeiro² \\ Monyzia de Souza Batista ${ }^{3}$ \\ Kelly Polyana Santos ${ }^{4}$
}

Resumo: Objetivou-se analisar a percepção ambiental dos feirantes do mercado público de Corrente/PI sobre a geração de resíduos sólidos. Participaram do estudo 20 feirantes. Os dados foram obtidos através de entrevistas semiestruturadas e os tratamentos estatísticos foram realizados no Excel. A maioria afirmou que a poluição e degradação do solo são as questões mais preocupantes, $15 \%$ dos feirantes já contraíram alguma doença por conta da proximidade com o lixo produzido na feira e $85 \%$ dos entrevistados se preocupam com as questões ambientais relacionadas ao descarte incorreto do lixo. Sugere-se que medidas preventivas junto à população e a todos os envolvidos nessa conjuntura possam ser efetivadas.

Palavras-chave: Educação Ambiental; Lixo Orgânico; Lixo Inorgânico; Degradação Ambiental; Reciclagem.

Abstract: The objective was to analyze the environmental perception of the generation of solid waste of fair dealers in the public market of Corrente, Piauí (Brazil). The data was obtained through semi-structured interviews and of twenty fair dealers and statistical treatments were performed in Microsoft Excel. The majority stated that pollution and soil degradation are the most worrying issues, $15 \%$ of the fair dealers have already contracted some disease due to the proximity to the garbage produced at the fair and $85 \%$ of the interviewed are concerned with environmental issues related to incorrect waste disposal. It is suggested that preventive measures with the population and all those involved in this situation can be put in practice.

Keywords: Environmental Education; Organic Waste; Inorganic Waste; Ambiental Degradation; Recycling.

\footnotetext{
1 Universidade Estadual do Piauí. E-mail: jobezerrasouzajh@gmail.com

2 Universidade Estadual do Piauí. E-mail: karen vel rib@hotmail.com

3 Universidade Estadual do Piauí. E-mail: monyziasouza@hotmail.com

${ }^{4}$ Universidade Estadual do Piauí. E-mail: kellypolyana@cte.uespi.br
} 


\section{Introdução}

A percepção ambiental vem sendo abordada em diversas áreas do conhecimento, proporcionando assim que cada vez mais pessoas fiquem informadas, e busquem a apreensão dos fatores, mecanismos e processos que possibilitam a construção de opiniões e atitudes em relação ao meio que estão vivendo. A percepção expressa um significado originário que é a compreensão de um determinado objeto real (BERGMANN, 2007).

O meio pelo qual as pessoas que compõem a sociedade adquirem seus conceitos e valores, bem como compreendem suas ações para com o meio ambiente, é o enfoque da percepção ambiental, segundo Robbins (1999), esta, compreende a maneira de como os indivíduos organizam e interpretam suas impressões sensoriais, a fim de dar sentido ao seu ambiente.

O estudo da percepção ambiental de uma comunidade configura-se em uma ferramenta essencial para a compreensão acerca de comportamentos vigentes e para o planejamento de ações que promovam a sensibilização e o desenvolvimento de posturas éticas e responsáveis perante 0 ambiente (MARCZWSKI, 2006).

No mundo moderno, a produção de resíduos sólidos vem aumentando numa escala considerável, causando vários problemas ao ambiente e à saúde pública, tornando-se uma das grandes preocupações ambientais, visto que a maioria dos centros urbanos encontra problemas para disposição dos resíduos. A estratégia de minimização destes, a partir dos princípios de redução, reutilização e reciclagem, é uma medida adequada para se introduzir, nesse contexto (RODRIGUES, 1998; SCHALCH et al., 2002; SANTOS, 2005; DIAS, 2008). Dessa forma, o estudo da percepção ambiental surge no sentido de entender os impactos gerados pela intensa produção de resíduos sólidos, como também promover uma maior conscientização da sociedade acerca desses problemas.

Nesse sentido, o trabalho baseou-se na seguinte problemática: Qual a percepção ambiental que os feirantes do mercado público de Corrente (PI) possuem acerca da produção e destino dos resíduos sólidos gerados na feira?

Nesse viés, objetivou-se com a pesquisa, analisar a percepção ambiental dos feirantes do mercado público de Corrente (PI) sobre a geração de resíduos sólidos, identificando as formas precisas de como essa percepção pode sensibilizar e conscientizar os trabalhadores da feira em fazer o descarte correto dos resíduos. Como objetivos específicos, têm-se: caracterizar o perfil socioeconômico dos feirantes; avaliar o conhecimento dos mesmos sobre os problemas causados pelo lixo no ambiente urbano; examinar a participação dos feirantes nos processos de coleta dos resíduos sólidos gerados no mercado público de Corrente $(\mathrm{PI})$ e verificar o nível de entendimento dos mercadores quanto às questões ambientais relacionadas ao dia a dia. 


\section{Material e Métodos}

\section{Área e População de estudo}

O município de Corrente está localizado no extremo sul do estado do Piauí, nas coordenadas geográficas de 10²6'36" de latitude Sul e de 4509'44" de longitude Oeste, estando a uma altitude de 438 metros (Figura 1). Possui área de $3.045,9 \mathrm{~km}^{2}$ e população estimada em 26.575 habitantes, residindo $60 \%$ de seus moradores na zona urbana. O nome da cidade se deu em homenagem ao rio que passa no referido local, possuindo homonímia de "O Rio Corrente" (IBGE, 2018).
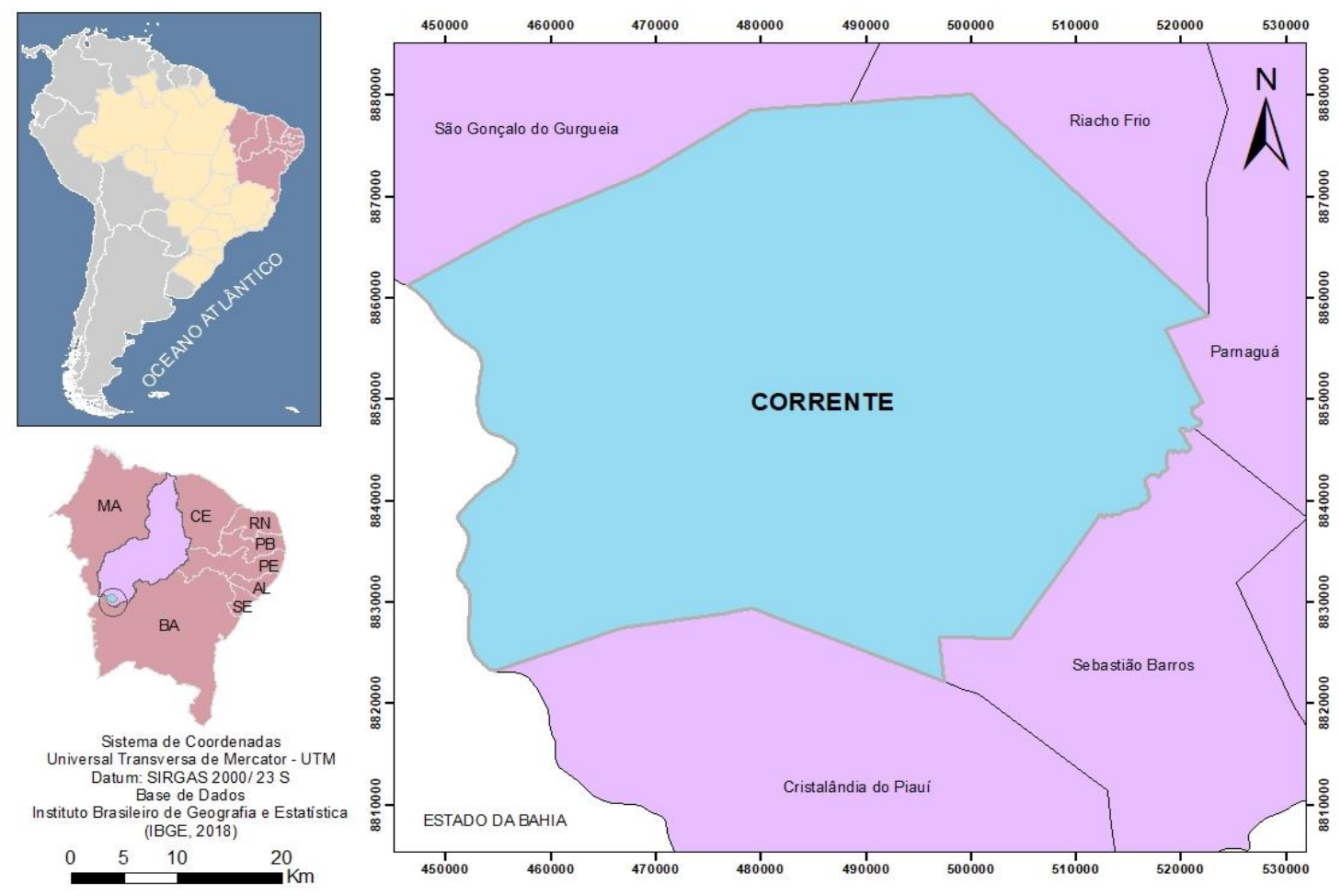

Figura 1: Localização do município de Corrente/PI.

Fonte: IBGE (2015), modificado por Karoline Veloso Ribeiro em 2019.

A pesquisa foi realizada no Mercado Público municipal da cidade de Corrente/PI, o qual possui, atualmente, cerca de 200 feirantes, estando endereçado na Rua Ipiranga, bairro Centro.

A comercialização acontece nas sextas-feiras (8:00h às 20:00h) e aos sábados (5:30h às 12:00h), com vendas de produtos da agricultura familiar, hortifrútis, produtos naturais, artesanais e carnes, em geral. Os produtos ficam expostos ou pendurados na estrutura da barraca, enquanto os produtos frigoríficos ficam acondicionados em freezers. 


\section{Coleta e Análise de dados}

O levantamento dos dados foi realizado por meio de visitas ao local, no período de janeiro de 2019 a dezembro de 2019. Os dados foram catalogados por meio de observação direta, anotações, registro fotográfico e entrevista semiestruturada (BERNARD, 1988), mediante aceite, conhecimento e assinatura do Termo de Consentimento Livre e Esclarecido (TCLE). Como instrumento norteador da pesquisa aplicou-se formulário com questões abertas e fechadas, o qual continha dados referentes a identificação do participante (ex: gênero, idade, escolaridade etc.), socioeconômica (ex: renda, profissão etc.) e a questão dos resíduos sólidos.

A fim de garantir o anonimato dos entrevistados, as transcrições de fala seguiram um código padrão, o qual foi apresentado da seguinte forma: E1, 30 anos; onde: "E" representa o (a) entrevistado (a), seguido do número da entrevista e idade do participante.

O universo amostral da pesquisa foi calculado segundo Barbetta (2006), tendo como amostragem geral 20 participantes. O critério de inclusão baseou-se no fato do feirante produzir uma quantidade significativa de lixo, ou seja, mercadores que geravam resíduos sólidos em uma proporção considerável foram eleitos para contribuírem com a pesquisa.

Os dados foram tabulados em planilhas do Microsoft Excel e analisados quali-quantitativamente. Em relação aos aspectos quantitativos, utilizou-se estatística básica, por meio de cálculos percentuais, os quais subsidiaram a discussão do presente estudo.

\section{Resultados e Discussão}

\section{Dados gerais e socioeconômico dos participantes}

Foram entrevistados 20 feirantes, dos quais $60 \%$ eram do sexo masculino e $40 \%$ do sexo feminino, com idades variando entre 18 a 78 anos. 0 perfil dos entrevistados demonstra que os homens participam mais ativamente do ofício de mercador, isso pode ser explicado pela intensa força física que precisam desempenhar para descarregar as caixas com os produtos destinados à venda.

Quando questionados sobre quantos anos trabalham na feira, a maioria (30\%) exerce a profissão por um período entre 6 a 10 anos (Figura 2). 


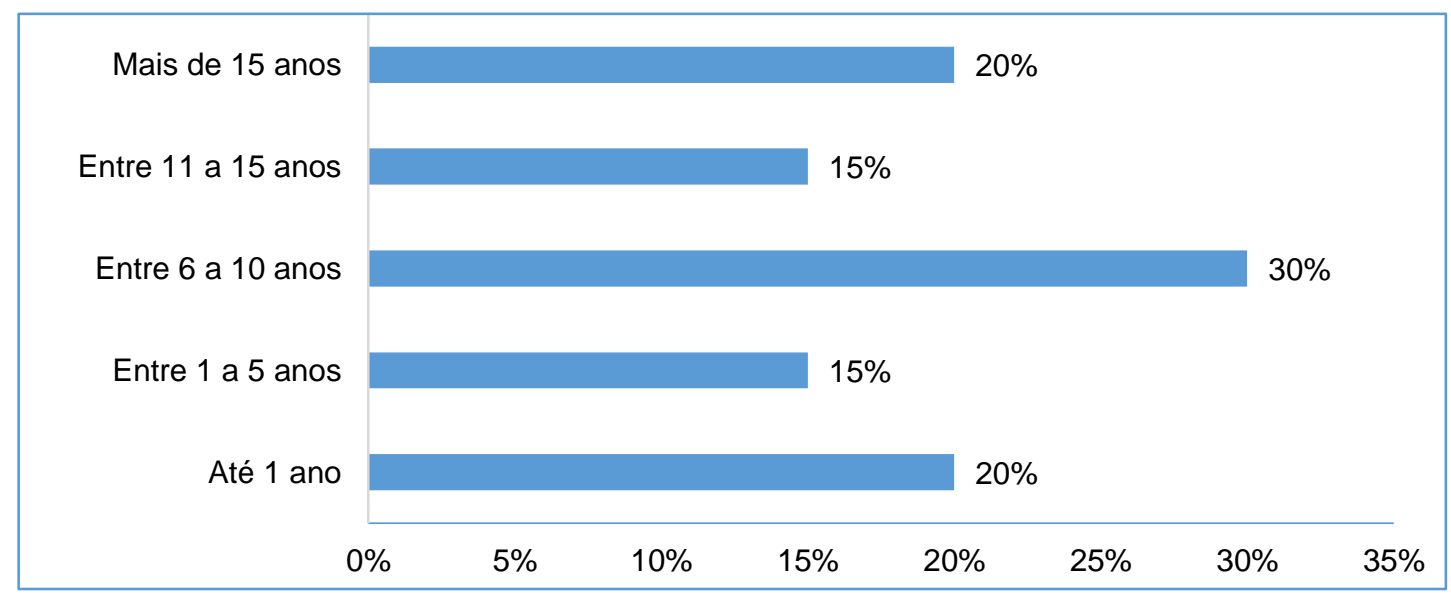

Figura 2: Tempo em anos de trabalho no mercado público municipal de Corrente.

Fonte: Pesquisa direta, 2019.

A escolaridade dos feirantes variou desde "Não Escolarizado" a "Ensino Superior Completo", sendo a maior representatividade o Ensino Fundamental Incompleto (40\%) (Figura 3). Resultados similares foram encontrados com outros feirantes de três feiras de Vitória no Espírito Santo: na feira do shopping Praia do Canto, 33\% não concluíram o ensino médio, na feira em Vila Velha, $50 \%$ dos feirantes ainda não concluíram o ensino fundamental e na feira realizada na Enseada do Suá, 33,3\% dos entrevistados não concluíram o ensino fundamental (BONADIMAN et al., 2017).

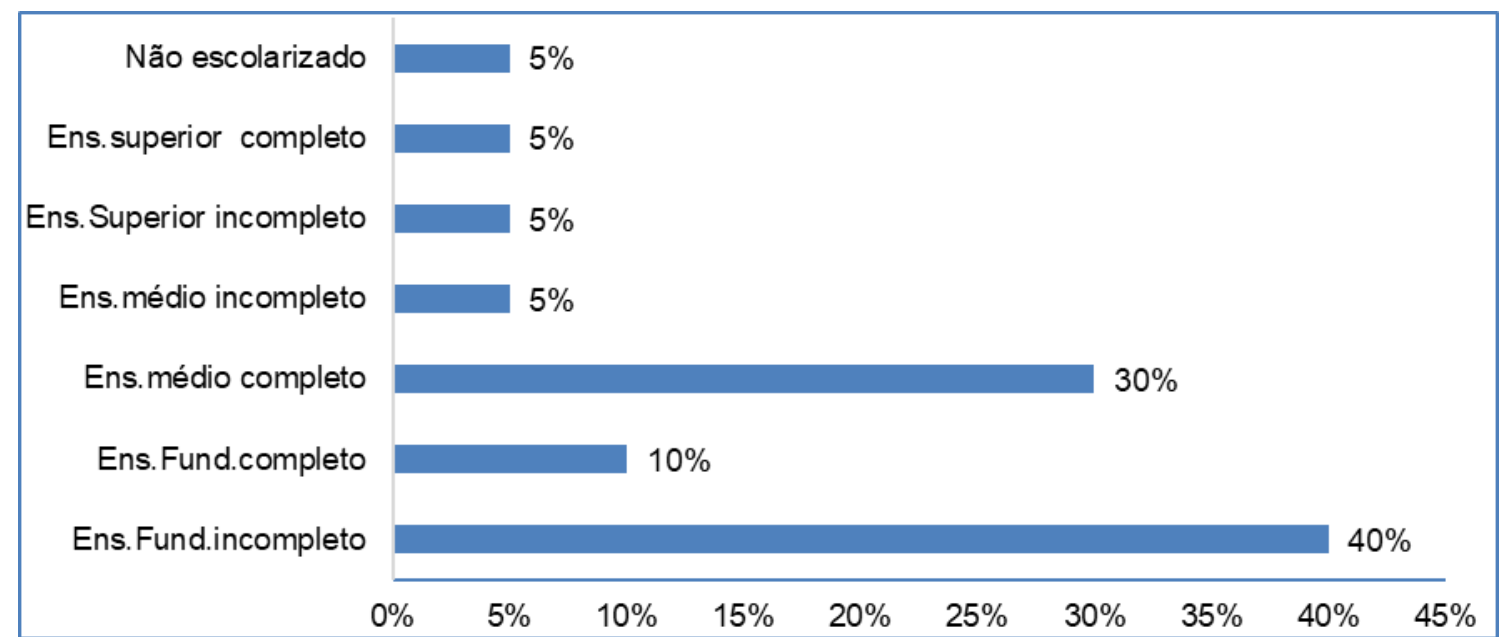

Figura 3: Grau de escolaridade dos entrevistados do mercado público municipal de Corrente.

Fonte: Pesquisa direta, 2019.

Os dados relacionados às questões socioeconômicas mostraram que a renda oriunda da feira variou entre $R \$ 100,00$ e $R \$ 6.000,00$. Para complementar a renda familiar, $40 \%$ dos feirantes desempenham atividades secundárias (ex: trabalham como serventes de pedreiro, outros possuem lojas físicas de vestuário etc.), perfazendo renda extra que variam de $\mathrm{R} \$ 700,00$ a $\mathrm{R} \$$ 6.000,00 (Ano base: 2019). 


\section{Percepção ambiental acerca dos resíduos sólidos}

Quando questionados sobre a definição de resíduos sólidos (Figura 4), (70\%) dos entrevistados afirmaram que "é tudo aquilo que não pode ser reaproveitado", enquanto $15 \%$ não souberam responder.

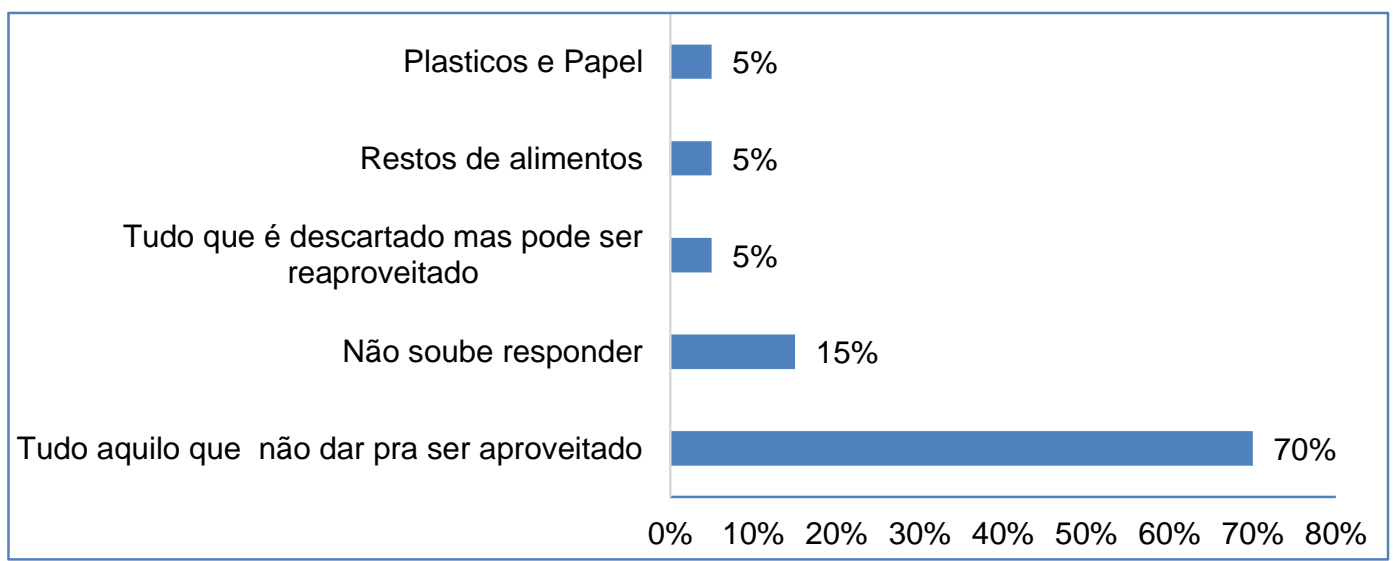

Figura 4: Definição de resíduos sólidos segundo os feirantes do mercado público municipal de Corrente. Fonte: Pesquisa direta, 2019.

Segundo Pichtel (2005), os resíduos sólidos são considerados materiais sólidos com valor econômico negativo, pois o seu descarte se torna mais barato que o seu reuso. Tal afirmação entra em contradição com os preceitos atuais que vigoram sobre o valor econômico dos resíduos, como observado na Lei ำ 12.305, de 2 de agosto de 2010, regulamentada pelo decreto 7.404, de 23 de dezembro de 2010, que dispõe sobre a Política Nacional dos Resíduos Sólidos (PNRS) no Brasil, o qual define resíduos sólidos como sendo todo material, substância, objeto ou bem descartado provenientes de atividades humanas em sociedade. Segundo Smith e Scott (2005), os resíduos sólidos incluem sobras comerciais de construções e demolições, resquícios industriais, domésticos etc., ficando excluídos os materiais de características importantes como, os perigosos e os radioativos.

A partir desses dados, ficou evidente que os feirantes não conseguem pormenorizar com exatidão tal definição, tendo em vista que alguns resíduos sólidos podem ser reaproveitados, não estando o seu conceito atrelado ao seu reuso ou não, mas ao seu descarte. O baixo grau de escolaridade dos voluntários pode ter influenciado nas suas respostas sobre o assunto em questão.

Quando questionados sobre a diferença entre resíduos sólidos orgânicos (Figura 5) e inorgânicos (Figura 6), 65\% dos entrevistados não souberam responder e 35\% abordaram diferentes concepções:

"Inorgânicos são o papel e os plásticos, e 
"Orgânicos é aquele que se decompõe na natureza e o inorgânico precisa de um componente químico" (E6, 38 anos).

"O orgânico serve como adubo, e os inorgânicos serve para a reciclagem" (E7, 48 anos).

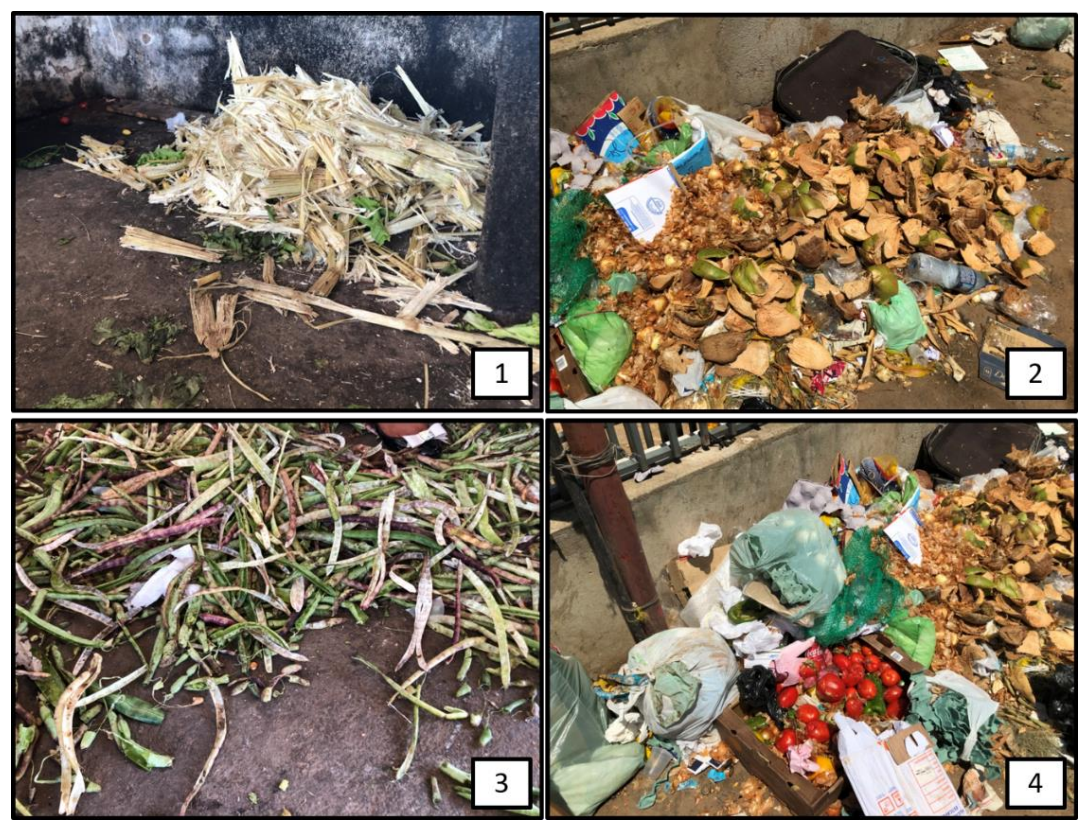

Figura 5: Resíduos sólidos orgânicos produzidos no mercado público municipal de Corrente. 1. Descarte de cana- de- açúcar; 2 . Descarte de coco; 3. Descarte de feijão; 4 . Descarte de tomates. Fonte: Pesquisa direta, 2019.

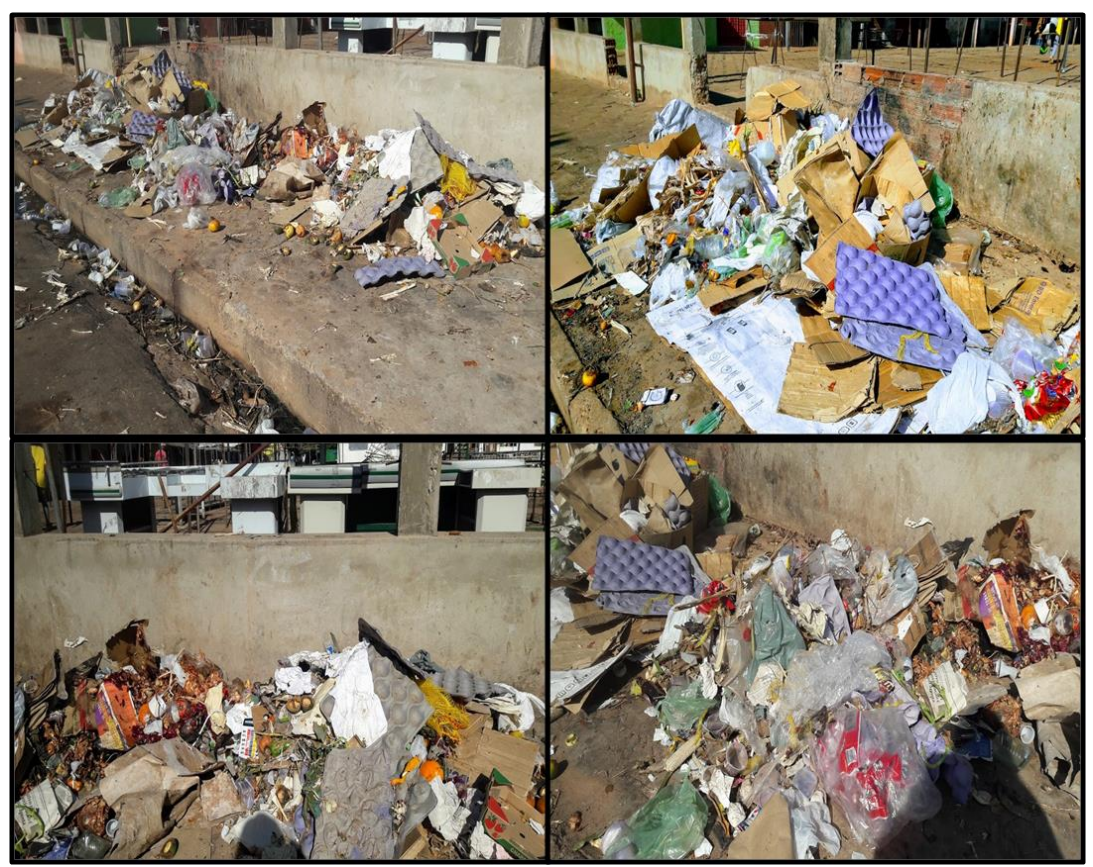

Figura 6: Resíduos sólidos inorgânicos produzidos no mercado público municipal de Corrente. Fonte: Pesquisa direta, 2019. 
Em conformidade com Gonçalves (2005), o lixo, em geral, é composto por diversos tipos de materiais e podem assumir tais características. Segundo o mesmo autor, o lixo orgânico engloba restos de comida, cascas de legumes, frutas, entre outros, correspondendo, nos países em desenvolvimento, de $65 \%$ a $70 \%$ do lixo gerado, enquanto que, o inorgânico (ex: papel, plásticos, garrafas pet, papelões, entre outros), consiste em materiais recicláveis que apresentam de $25 \%$ a $30 \%$ do volume residual gerado, já os rejeitos (ex: pilhas, lâmpadas, resíduos de banheiro, entre outros), correspondem a $5 \%$ do volume gerado, não sendo passível de reciclagem ou reuso. De acordo com essas informações, pode-se perceber que os relatos supramencionados dos feirantes corroboram com o que pressupõe a literatura, embora apenas uma pequena minoria (35\%) consiga discerni-lo e/ou tem noção do que vem a ser um resíduo sólido orgânico e inorgânico.

Quando indagados se há aproveitamento do lixo orgânico na feira, $65 \%$ dos entrevistados afirmaram que o mesmo não é aproveitado, enquanto que $35 \%$ deles responderam que é, sendo inclusive usado para fins diversos, como observado nos relatos a seguir:

"Leva para os animais" (E4, 28 anos).

"Reaproveita como ração animal" (E10, 38 anos).

Para os $65 \%$ dos feirantes que afirmaram que o lixo orgânico produzido na feira não é reaproveitado para nenhum fim, confirmaram ainda, que este acaba sendo depositado na calçada da parte de trás (fundo) do mercado, tornando-se veículo de propagação de doenças e poluindo o ambiente. Logo, somente uma pequena parcela dos entrevistados (35\%) recolhem resíduos de interesse, para alimentar os animais e servir de insumos para a ração animal. Dados similares foram encontrados por Sousa et al. (2017), ao pesquisar sobre a geração de resíduos sólidos orgânicos na feira da Prata, em Campina Grande/PB. De acordo com os colaboradores deste estudo, os resíduos orgânicos não possuem uma destinação final ambientalmente adequada, com exceção de uma pequena quantidade que é destinada à alimentação de porcos, uma vez que nem todos os feirantes destinam os seus resíduos para esta finalidade, visto que são os próprios criadores que fazem a coleta sem nenhum planejamento ou gerenciamento do material recolhido. Ainda em conformidade com os mesmos autores, os criadores desses animais não possuem parceria com os feirantes como também não a possuem com a administração da feira, logo, ao final de cada expediente, os resíduos coletados por eles são destinados a constituírem a lavagem dos suínos como também usados para compor ração para alimentação de gado.

Quando às principais consequências do acúmulo do lixo no meio ambiente, a maioria (13 citações) afirmou que a poluição e degradação do solo são questões mais preocupantes (Figura 7). 


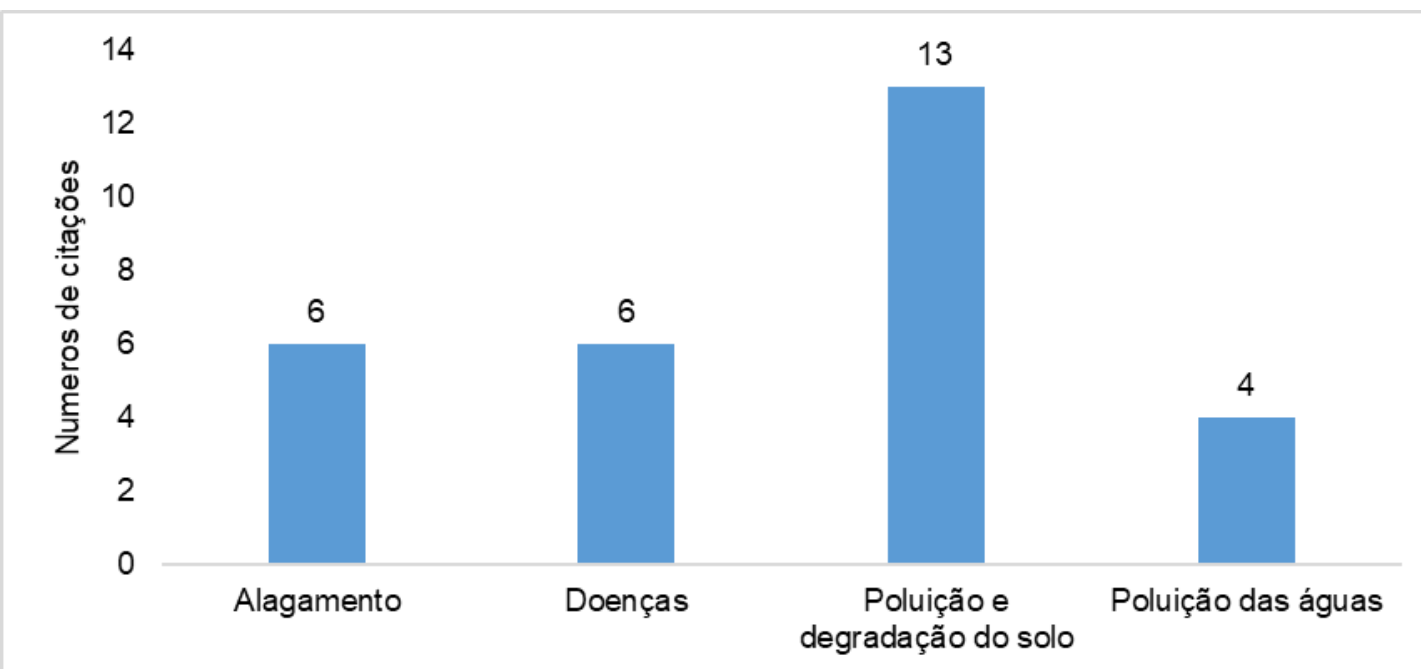

Figura 7: Consequências do acúmulo dos resíduos no meio ambiente segundo os feirantes do mercado público municipal de Corrente. Fonte: Pesquisa direta, 2019.

Apesar dos feirantes terem conhecimento sobre os impactos ambientais ocasionados pelo descarte irregular dos resíduos, observou-se que poucos realmente se preocupam com as questões ambientais. Muitos deles descartam seus resíduos de forma incorreta sem a preocupação de que esta ação está contribuindo para propagação de doenças e/ou para a poluição da sua própria cidade. Incentivos governamentais associados a medidas socioeducativas nas feiras livres podem consistir em prerrogativas mitigatórias frente aos efeitos negativos oriundos do acúmulo de lixo no meio. Para que isso aconteça, ações emergenciais para salvar o planeta e melhorar as condições de saúde e higiene da população de Corrente precisam ser adotadas como: sensibilizar as pessoas diante da importância da coleta seletiva, uma vez que constitui uma prática simples e de grande valia para o meio ambiente.

Segundo Floriano (2016), a questão do lixo e das feiras livres refere-se a aspectos de natureza pública, por entender que a gestão dos mercados e de seus resíduos compete a todos, mas especialmente ao poder público municipal, por meio de medidas de prevenção e correção. Nesse viés, Loureiro et al. (2009) observaram a necessidade de desencadear nos indivíduos a conscientização em relação ao ambiente e, principalmente, em relação à quantidade de resíduos sólidos que afetam o meio e os seres que nele vivem, destacando a importância do conhecimento prematuro relativo aos resíduos sólidos, a partir dos desafios colocados pela sociedade. Isto é, o indivíduo tem que adotar um novo comportamento em relação a si mesmo e ao meio em que vive, pois é da natureza que eles obtêm o seu sustento.

Quando indagados sobre as doenças que podem ser transmitidas pelo lixo (Figura 8), 35\% dos feirantes entrevistados não souberam responder, enquanto que $50 \%$ relataram dengue e leptospirose ( $25 \%$ cada). 


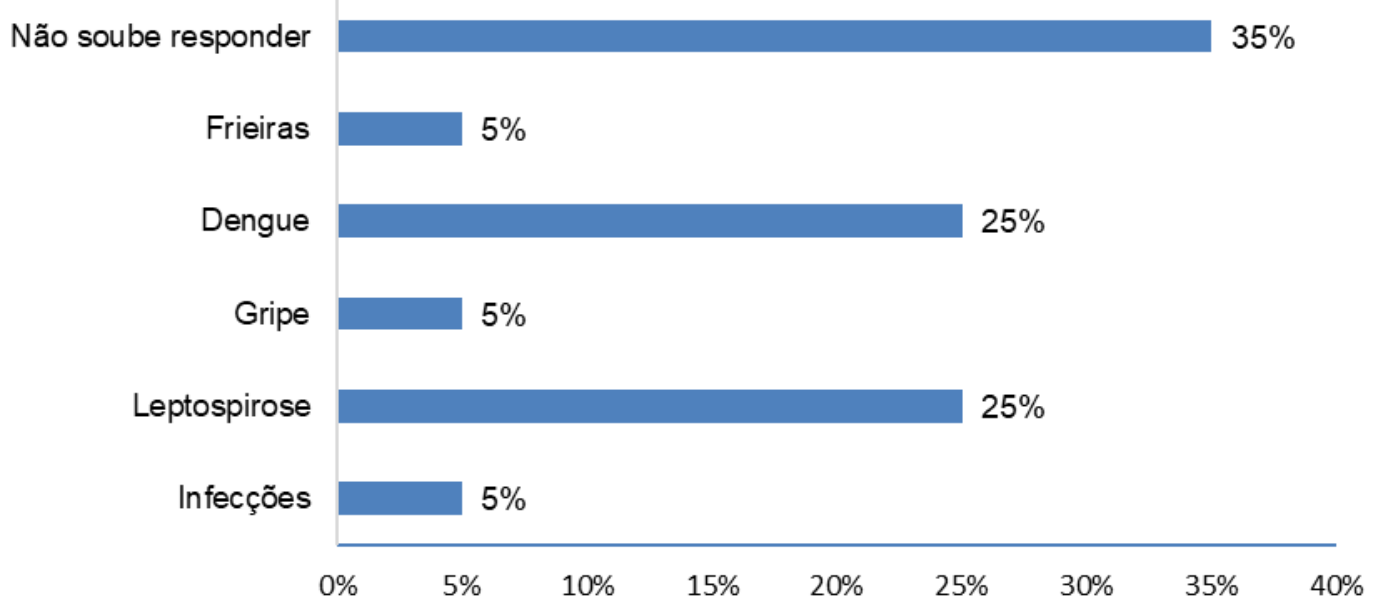

Figura 8: Doenças transmitidas por meio do lixo de acordo com os feirantes do mercado público municipal de Corrente. Fonte: Pesquisa direta, 2019.

De acordo com Almeida e Pena (2011), os feirantes e consumidores das feiras livres ficam imersos em um ambiente poluído, caracterizado pelo mau cheiro e pela presença de restos de alimentos jogados pelo chão, os quais acabam atraindo e servindo de criatório para diversos animais. Segundo a Fundação Nacional de Saúde (FUNASA, 2013), esse ambiente se torna propício para a proliferação de agentes causadores de doenças, tornando-se uma questão de saúde pública, por promover fator de risco para a saúde humana.

Minnaert e Freitas (2010) advertem que somente remover o lixo e a sujeira da feira não será suficiente para o afastamento do perigo a saúde, devido aos feirantes já estarem habituados a conviverem com o mau cheiro e lixo espalhado no seu local de trabalho. Muitas vezes a limpeza está associada também a higiene pessoal, que é essencial para a aparência do local, principalmente quando se trata de alimentos perecíveis. Pois sabe-se que a maioria das infecções, podem igualmente ser acarretadas pelo manuseio incorreto dos alimentos.

Quanto à contaminação ou aquisição de alguma enfermidade por conta da proximidade com os resíduos sólidos, $15 \%$ relataram que ficaram doentes, destacando-se as enfermidades: gripe e dengue. A gripe é uma virose facilmente veiculada por partículas de secreção infectadas suspensas no ar, principalmente, em locais onde há aglomerados de pessoas, como é o caso das feiras livres, enquanto, os resíduos sólidos descartados incorretamente nesse mesmo ambiente, podem servir de criatório de vetores de doenças, a exemplo da dengue, zika, entre outras enfermidades.

Em conformidade com a Resolução RDC no 216/2004 (ANVISA, 2004), os locais onde há manipulação de alimentos devem possuir lavatórios e estarem supridos de produtos de higiene pessoal. No entanto, Pinto et al. 
(2019) mencionam, que a falta de uma legislação específica sobre a estrutura das feiras livres não assegura condições adequadas de higienização pessoal e dos alimentos durante sua mercantilização, favorecendo a exposição e contaminação por microrganismos.

No quesito coleta seletiva do lixo, $55 \%$ dos participantes afirmaram que é ruim; $30 \%$ disseram que é ótima e 15\% afirmaram que a feira não possui coleta seletiva. Após o término da feira, os feirantes descartam todos os seus resíduos na calçada (situada ao fundo do mercado), onde permanecem ali por muitos dias, até serem coletados, em parte, por pessoas que vão em busca de resíduos que possam ser reaproveitados ou, em sua totalidade, pelos coletores do município (garis). Entretanto, a coleta por estes últimos é feita sem que haja separação do que é orgânico e inorgânico ou do que pode ou não ser reutilizado ou reciclado, sendo recolhido todo misturado.

Em relação ao gerenciamento de resíduos sólidos, a PNRS (2010) estabelece, que para os mesmos devem ser obedecidas às seguintes etapas: reutilização, reciclagem, tratamento dos resíduos sólidos e disposição final ambientalmente adequada dos rejeitos. No entanto, a partir do exposto, observou-se que os feirantes não estão preocupados em seguir o ordenamento proposto pelo órgão que legisla sobre os resíduos sólidos. De acordo com Sousa et al. (2017), faltam medidas que incentivem a mitigação desses resíduos, bem como políticas de reutilização e reciclagem do material descartado.

Quando questionados, sobre o que eles fazem com o lixo que produzem no seu local de trabalho, constatou-se que os feirantes não utilizam métodos adequados para a destinação final dos resíduos, apesar de 35\% deles afirmarem que o fazem em locais corretos (Figura 9).

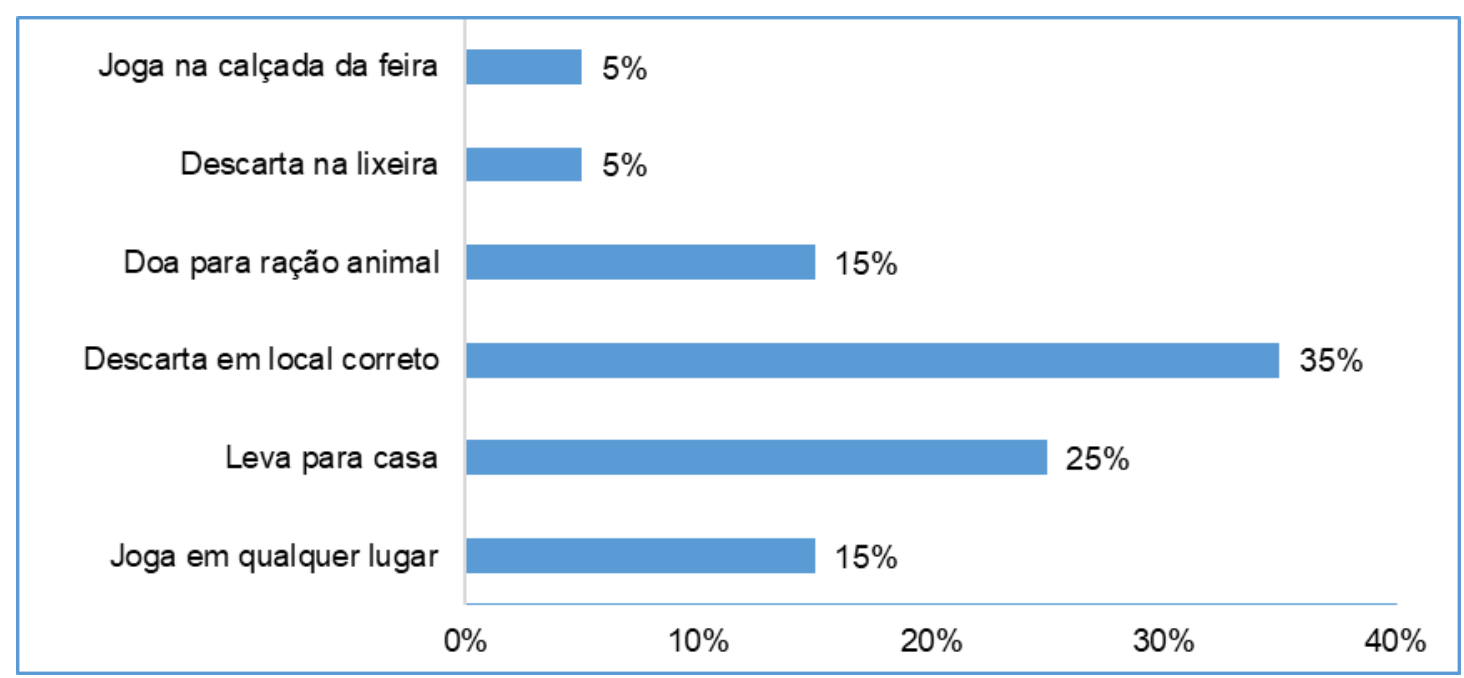

Figura 9: Forma de descarte do lixo produzido pelos feirantes do mercado público municipal de Corrente. Fonte: Pesquisa direta 2019. 
Com exceção daqueles que doam os resíduos orgânicos para ração animal (15\%), que ainda seleciona o que vai ser reaproveitado, todos os demais não possuem a preocupação de separá-los, descartando tudo na mesma lixeira ou ainda, em locais inapropriados. Holanda et al. (2017) também relataram em seus estudos sobre gerenciamento dos resíduos sólidos na feira do mercadão 2.000 em Santarém/PA, que no local não há separação dos resíduos orgânicos dos inorgânicos.

Souza (2004) afirma que o descarte incorreto dos resíduos gerados em grande escala é um dos maiores problemas na sociedade atual, sendo os maiores causadores de poluição, degradação e desequilíbrio ambiental. $O$ mesmo ainda aponta, que é necessário sensibilizar as pessoas, de que os resíduos sólidos depositados a céu aberto desencadeiam diversos tipos de poluição e, um dos poluentes mais agressivos para a natureza é o chorume, produzido após a decomposição da matéria orgânica, podendo contaminar os rios, o solo, o ar e os lençóis freáticos.

Oliveira (2006) ratifica, que se os resíduos sólidos fossem inseridos em locais apropriados, o nível de poluição seria consideravelmente reduzido e os problemas sanitários seriam minimizados e se tornariam favoráveis às populações.

No tocante a quantidade de lixo que é gerado na feira semanalmente, a maioria (30\%) afirmou que esse valor atinge cerca de uma tonelada e $20 \%$ não souberam responder (Figura 10).

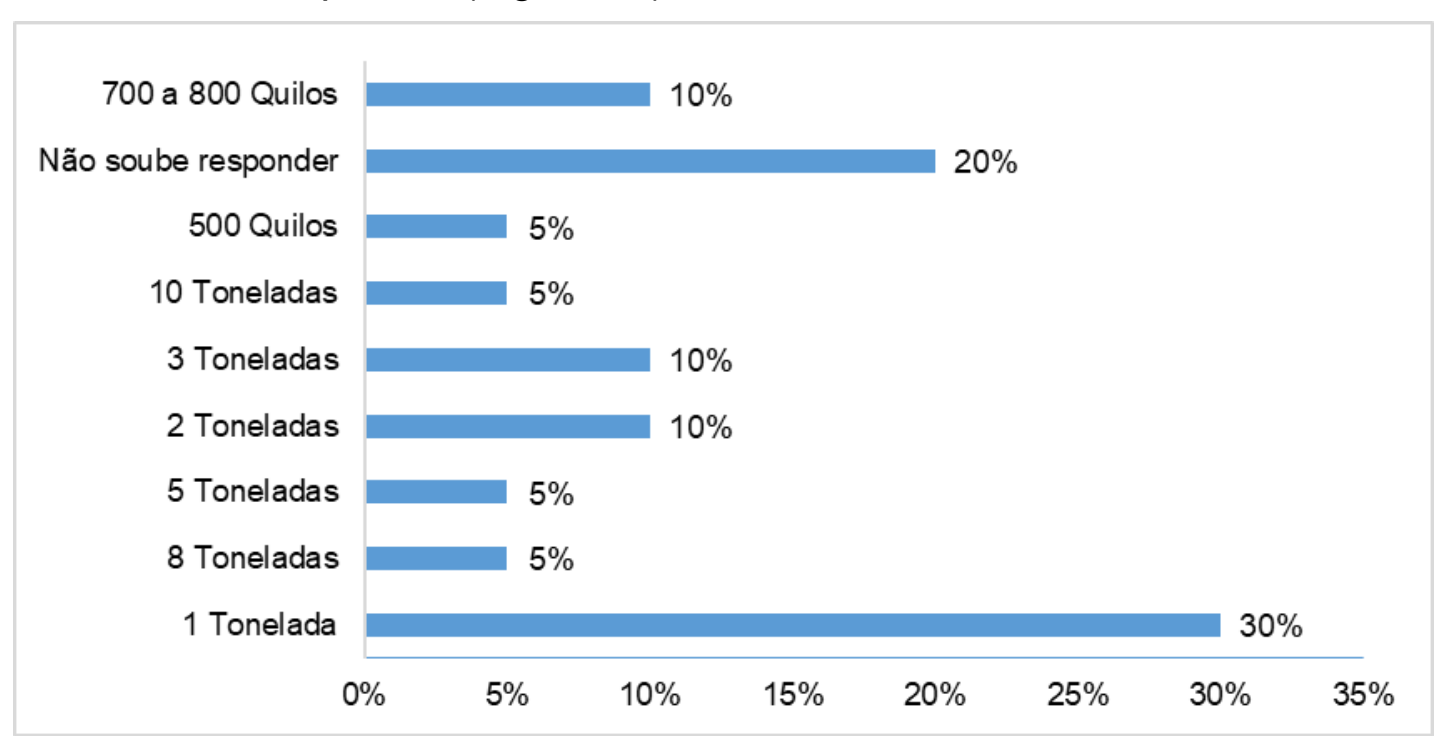

Figura 10: Quantidade de lixo que é gerado na feira semanalmente, segundo os feirantes do mercado público municipal de Corrente/PI.

Fonte: Pesquisa direta 2019. 
Holanda et al. (2017) não foi possível mensurar a quantidade de resíduo produzido diariamente, em virtude de a associação responsável pela limpeza não ter realizado nenhuma pesagem para confirmar os dados. Já nos estudos de Rangel et al. (2016), são gerados diariamente, cerca de 10 toneladas de resíduos sólidos na feira livre do município de Solânea/PB. De acordo com a literatura pode-se inferir, que o valor total de resíduo produzido pode estar vinculado ao tamanho do estabelecimento, número de compartimentos e quantidade de feirantes presente no local.

Em todo o período em que as feiras livres acontecem, observa-se uma grande geração de lixo produzido pelos feirantes, desde a montagem de suas barracas, momento em que os alimentos são selecionados para ficarem expostos e disponíveis para venda até o desmonte das mesmas, ao final do expediente, gerando uma grande quantidade de resíduos sólidos orgânicos e inorgânicos no ambiente (FERREIRA et al., 2015). Em conformidade com estes mesmos autores, os resíduos orgânicos são os mais desperdiçados, pois muitas vezes não são aproveitados como deveriam.

Foi verificado também, que $85 \%$ dos entrevistados se preocupam com as questões ambientais relacionadas ao descarte incorreto do lixo. Tais preocupações ficaram evidenciadas nos relatos que seguem:

"Porque causam problemas de saúde e no meio ambiente" (E17, 48 anos).

"Porque causam doenças e mal cheiro" (E16, 48 anos).

A educação, segundo o Núcleo de Educação e Monitoramento Ambiental (NEMA) et al. (2008), é considerada o principal veículo pelo qual se pode buscar a transformação desta prática e posterior sensibilização em torno dos problemas ambientais ocasionados pelo descarte irregular dos resíduos sólidos em feiras livres.

Quando questionados para onde os resíduos sólidos gerados na feira são destinados, $60 \%$ dos entrevistados afirmaram que vão para o lixão, enquanto $40 \%$ não souberam responder. Lixões caracterizam-se pelo simples descarte de resíduos sobre o solo, sem nenhum tipo de manejo técnico e medidas de proteção ao meio ambiente. Essa forma de descarte de resíduos é considerada inadequada e ilegal pela legislação brasileira. Os lixões a céu aberto desencadeiam problemas de saúde pública, pois tornam-se locais propensos ao aparecimento de animais e insetos transmissores de doenças, como: moscas, baratas, mosquitos, ratos, entre outros, além de emanarem odores desagradáveis, poluírem o solo e as águas, a partir de um composto produzido pela decomposição da matéria orgânica, o chorume (LUCAS FILHO; LINHARES, 2019). 
Nos estudos de Rangel et al. (2016) todo o resíduo sólido apanhado na feira de Solânea, na Paraíba, é acondicionado sem nenhuma seleção ou separação e, em seguida, é levado por meio de caçambas para o lixão da localidade, sem passar por nenhum tipo de triagem, seleção ou tratamento. Cunha (2011) afirma, que sem políticas públicas eficientes não têm como oferecer uma destinação correta a esses resíduos, dessa forma, são criadas soluções improvisadas de caráter emergencial, as quais repercutirão e darão origem a vários outros transtornos, refletindo assim, em uma série de problemas de saúde e ambientais.

Quando à fonte de informações acerca dos resíduos sólidos, $50 \%$ responderam que obtiveram de conversas informais com outras pessoas (Figura 11). Os livros consistiram no veículo de informação menos citado pelos entrevistados (5\%).

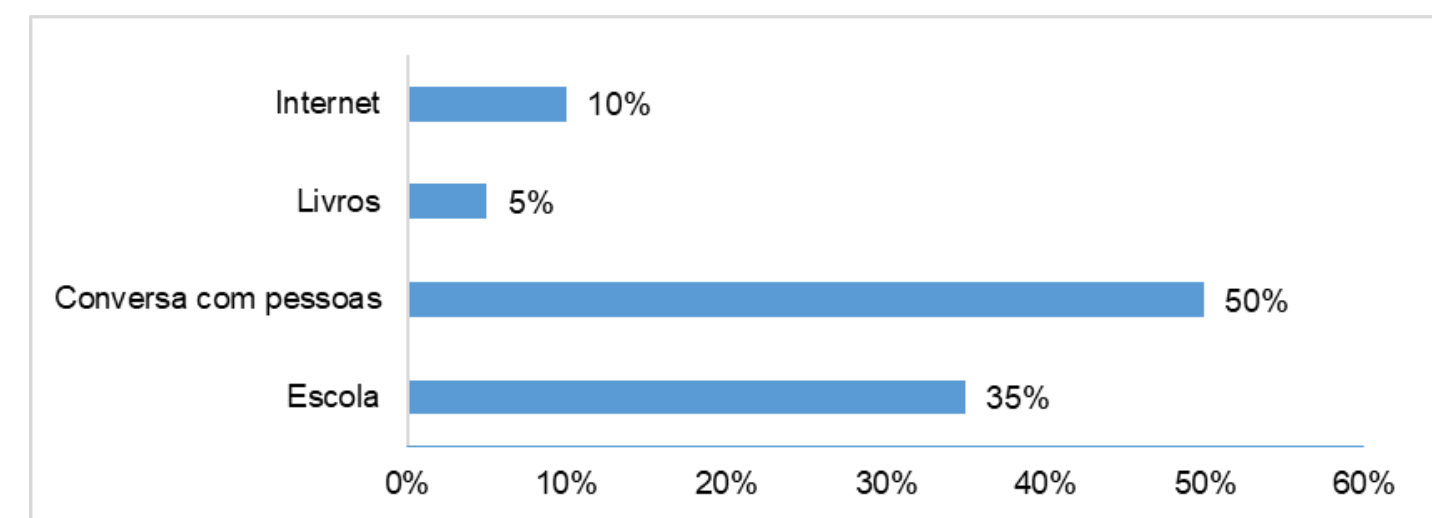

Figura 11: Principal fonte de conhecimento dos entrevistados do mercado público de Corrente sobre os resíduos sólidos. Fonte: Pesquisa direta 2019.

A educação ambiental é um dos temas transversais de todas as disciplinas curriculares devendo ser abordado em todos os níveis, etapas e modalidades. $\mathrm{Na}$ ausência dessa abordagem, outros mecanismos podem ser utilizados no preparo desses atores sociais em relação ao tema proposto. Pinto et al. (2019) elencaram uma série de medidas relativamente simples que podem auxiliar significativamente para minimizar os problemas relativos aos resíduos sólidos em feiras livres, como: proporcionar cursos de capacitação para os feirantes, sobre higiene pessoal, manipulação correta dos alimentos e gerenciamento dos resíduos, a fim de colocar em prática os $4 \mathrm{R}$ (repensar, reduzir, reutilizar e reciclar); fomentar parcerias com ONGs para captação e reaproveitamento dos alimentos descartados; aproveitar as "sobras" para compostagem, forragem e etc., entre várias outras providências de cunho socioambiental.

De modo geral, a caracterização dos resíduos sólidos e seu atual gerenciamento, consistem em passos iniciais para tomadas de decisões adequadas quando há o envolvimento de todos os envolvidos nesse processo, 
desde a coleta até o destino final desse resíduo. Assim, uma das propostas para incrementar o comportamento ecológico é a sensibilização ambiental, bem como, o planejamento de ações de educação ambiental e políticas públicas que se aproximem da realidade dos cidadãos (SCHAWB et al., 2014).

\section{Conclusão}

Conclui-se que a maioria dos feirantes possui conhecimento acerca das questões ambientais relacionadas ao descarte incorreto dos resíduos sólidos, sendo parte destes reaproveitados para outras finalidades pelos próprios feirantes ou doados a terceiros.

Também ficou evidente que não existe coleta seletiva por parte dos feirantes e que eles não conseguem distinguir resíduos sólidos orgânicos dos inorgânicos, em sua maioria. Nota-se ainda, que boa parte deles não consegue mensurar os danos que esses resíduos provocam no ambiente, apesar de saberem relatar os problemas que estes ocasionam no meio.

No sentido de amenizar os desequilíbrios ambientais e os casos de saúde pública intimamente inter-relacionados, sugere-se que medidas preventivas junto à população e a todos os envolvidos nessa conjuntura possam ser levadas mais a sério e realmente efetivadas, a fim de que promova uma sensibilização frente a essa questão, para que assim, sejam capazes de manter uma postura consciente acerca da má destinação dos resíduos sólidos, buscando dessa forma, minimizar os impactos negativos causados pelos mesmos.

\section{Referências}

ALMEIDA, M. D.; PENA, P. G. L. Feira livre e risco de contaminação alimentar: estudo de abordagem etnográfica em Santo Amaro, Bahia. Revista Baiana de Saúde Pública, 35(1):110-27, jan/mar, 2011.

AGÊNCIA NACIONAL DE VIGILÂNCIA SANITÁRIA. Resolução RDC no 216/2004. Dispõe sobre Regulamento Técnico de Boas Práticas para Serviços de Alimentação. Diário Oficial da União, Brasília, p. 1-14, set/2004.

BARBETTA, P. A. Estatística aplicada ás Ciências Sociais. Santa Catarina, Editora da UFSC, 2006. 315p.

BERGMAN, M. Análise da percepção ambiental da população ribeirinha do Rio Santo Cristo e de estudantes e professores de duas escolas públicas, município de Giruá, RS. 2007. Dissertação (Mestrado em Ecologia), Universidade Federal do Rio Grande do Sul, Porto Alegre, 2007.

BERNARD, $H$. R. Research methods in cultural anthropology. Sage Publications, Newbury Park, 1988. 520p. 
BRASIL. Lei no 12.305, de 2 de agosto de 2010. Institui a Política Nacional de Resíduos Sólidos; altera a Lei no 9.605, de 12 de fevereiro de 1998; e dá outras providências. Diário Oficial da União, Brasília, p.1-3, ago/2010.

BRASIL. Decreto no 7.404/2010. Regulamenta a Lei no 12.305, de 2 de agosto de 2010. Institui a Política Nacional de Resíduos Sólidos, cria o Comitê Interministerial da Política Nacional de Resíduos Sólidos e o Comitê Orientador para a Implantação dos Sistemas de Logística Reversa, e dá outras providências. Diário Oficial da União, Brasília, p.1-9, dez/2010.

BONADIMAN, P. A., CUNHA, E. G., FRIZZERA JUNIOR, J. L., DALBOM, F. L.; PREZOTTI, L. Percepção dos feirantes sobre as novas feiras agroecológicas da Grande Vitória - ES. Cadernos de Agroecologia, Brasília, 13(1):1-7, set/2018.

NÚCLEO DE EDUCAÇÃO E MONITORAMENTO AMBIENTAL - NEMA. Agroecologia: um caminho amigável de conservação da natureza e valorização da vida. Rio Grande, NEMA, 2008. 28p.

CUNHA, B. S. Direitos fundamentais: da constituição às políticas públicas. Revista Brasileira de Políticas Públicas, Brasília, 1(1):65-82, jan/jun, 2011.

DIAS, R. Turismo sustentável e meio ambiente. São Paulo, Atlas, 2008. 208p.

FERREIRA, M. G., FERREIRA, C. S., PEREIRA, S. F. P., SILVA, C. S., SANTOS, D. C., OLIVEIRA, A. F. S., OLIVEIRA, J. S.; OLIVEIRA, G. R. Anais do XV Safety, Health and Environment World Congress - no período de julho 2015, Porto: COPEC, p. 19-22, 2015.

FLORIANO, C. S. A problemática dos resíduos sólidos na feira livre de Guarabira/PB. 2016. Monografia (Graduação em Geografia), Universidade Estadual da Paraíba, Guarabira, 2016.

FUNDAÇÃO NACIONAL DE SAÚDE - FUNASA. Resíduos sólidos - 2013. FUNASA. Disponível em:<http://www.funasa.gov.br/saneamento-parapromocao-da-saude>. Acesso em: 8 nov. 2019.

GONÇALVES, R. C. M. A voz dos catadores de lixo em sua luta pela sobrevivência. 2005. Dissertação (Mestrado em Políticas Públicas e Sociedade), Universidade Estadual do Ceará, Fortaleza, 2005.

HOLANDA, R. O., RODRIGUES, M. E.; SANTOS, A. G. P. Gerenciamento dos resíduos sólidos na feira do Mercadão 2.000, em Santarém - PA. Anais do VIII Congresso Brasileiro de Gestão Ambiental - no período de novembro - 2017, Campo Grande: CNMA, p. 1-6, 2017.

INSTITUTO BRASILEIRO DE GEOGRAFIA E ESTATÍSTICA - IBGE. Cidades 2018. Rio de Janeiro. Disponível em:<https://cidades.ibge.gov.br/brasil/pi/corrente/panorama> . Acesso em: 28 nov. 2019. 
LOUREIRO, C. F. B., LAYRARGUES, P. P.; CASTRO, R. S. Repensar a educação ambiental: um olhar crítico. Cortez, São Paulo, 2009. 206p.

LUCAS FILHO, A.; LINHARES, E. L. R. Disposição final dos resíduos sólidos: um estudo de caso no Alto Oeste Potiguar IBEAS - Instituto Brasileiro de Estudos Ambientais. Anais do X Congresso Brasileiro de Gestão Ambiental no período de novembro - 2019, Fortaleza: CBGA, p. 1-9, 2019.

MARCZWSKI, M. Avaliação da percepção ambiental em uma população de estudante do Ensino Fundamental de uma escola municipal rural: um estudo de caso. 2006. Dissertação (Mestrado em Ecologia), Universidade Federal do Rio Grande do Sul, Porto Alegre, 2006.

MINNAERT, A. C. S. T.; FREITAS, M. C. S. Práticas de higiene em uma feira livre na Cidade de Salvador (BA). Revista Ciência e Saúde Coletiva, 15(1):1607-1614, 2010.

OLIVEIRA, N. A. S. A percepção dos resíduos sólidos (lixo) de origem domiciliar no Bairro Cajuru, Curitiba-PR: um olhar reflexivo a partir da educação ambiental. 2006. Dissertação (Mestrado em Geografia), Universidade Federal do Paraná, Curitiba, 2006.

PICHTEL, J. Waste management practices: municipal, hazardous, and industrial. Taylor \& Francis, Boca Raton, 2005. 688p.

PINTO, H. A. S., PONTES JUNIOR, A. F., ABRANTES, P.; BARRELLA, W. Diagnóstico e gerenciamento de resíduos em feiras livres do Município de Santos/SP. UNISANTA Bioscience, 8(1):96-111, 2019.

RANGEL, M. D. F., RANGEL, M. D. F., RANGEL, I. S. L., DANTAS, A. C., MEDEIROS, M. G., MARINHO, A. S.; NOGUEIRA, N. S. Gestão dos resíduos gerados na feira livre do município de Solânea-PB. Anais do Congresso Brasileiro de Gestão Ambiental e Sustentabilidade - no período de dezembro 2016, João Pessoa: CONGESTAS, p. 565-571, 2016.

ROBBINS, S. Comportamiento organizacional. Prentice-Hall, México, 1999. $675 p$.

RODRIGUES, A. M. Produção e consumo do e no espaço: problemática atual urbana. Hucitec, São Paulo, 1998. 239p.

SANTOS, C. L. Prevenção a poluição industrial: identificação de oportunidades, análise de benefícios e barreiras. 2005. Tese (Doutorado em Ciências da Engenharia Ambiental), Universidade de São Paulo, São Carlos, 2005.

SCHWAB, N., HARTON, H. C.; CULLUM, J. G. The effects of emergent norms and attitudes on recycling behavior. Environment and Behavior, 46(4):403422, mai/2014.

SMITH, P.G.; SCOTT, J. S. Dictionary of water and waste management. Elsevier, Amsterdam, 2005. 480p. 
SCHALCH, V., LEITE, W. C. A., FERNANDES JÚNIOR, J. L.; CASTRO, M. C. A. A. Gestão e gerenciamento de resíduos sólidos. Escola de Engenharia de São Carlos - USP, São Carlos, 2002. 92p.

SOUSA, G. M., SANTOS, V. S., OLIVEIRA, F. F. D., ARAUJO, B. J. B. L.; FIGUEIREDO, C. F. V. O estudo da geração de resíduos sólidos orgânicos: na feira da Prata da cidade de Campina Grande. Revista Brasileira de Gestão Ambiental, Pombal, 11(1):162-167, jan/dez, 2017.

SOUZA, M. N. Degradação e recuperação ambiental e desenvolvimento sustentável. 2004. Tese (Doutorado em Ciência Florestal), Universidade Federal de Viçosa, Viçosa, 2004. 